\title{
Studies on Influence of WC on Scratch and Hot Corrosion Resistance of AISI H13 Steel by Flame-Sprayed Coatings of EWAC 1001
}

\author{
K. Gokul Kumar and N. Arivazhagan \\ School of Mechanical and Building Sciences, VIT University, Vellore 632 014, India \\ Correspondence should be addressed to N. Arivazhagan, narivazhagan@vit.ac.in
}

Received 9 August 2011; Accepted 5 September 2011

Academic Editors: N. Bahlawane and C. Ribeiro

Copyright $\odot 2011$ K. Gokul Kumar and N. Arivazhagan. This is an open access article distributed under the Creative Commons Attribution License, which permits unrestricted use, distribution, and reproduction in any medium, provided the original work is properly cited.

\begin{abstract}
This paper presents the experimental investigations carried out to study the influence of addition of Tungsten Carbide (WC) on the scratch resistance and high-temperature corrosion behaviour of flame-sprayed EWAC 1001 coatings on the AISI H13 steel substrate. The improvement in properties was analysed by conducting various tests such as microstructural analysis, microhardness, and scratch tests. Moreover, high-temperature corrosion tests were carried out on the coated as well as uncoated AISI H13 steel by exposing the material to air oxidation at $700^{\circ} \mathrm{C}$ under cyclic conditions. The thermogravimetric technique was used to establish kinetics of corrosion, whereas XRD and SEM/EDAX techniques which were used to analyze the AISI H13 steel with EWAC 1001 coating containing WC showed better resistance to high-temperature corrosion as compared to that of uncoated AISI H13 steel. It is observed that the formation of $\mathrm{Cr}_{2} \mathrm{O}_{3}, \mathrm{NiO}$, and $\mathrm{NiCr}_{2} \mathrm{O}_{4}$ contributes to the enhancement of high temperature corrosion resistance of the coating. The formation of unprotective $\mathrm{Fe}_{2} \mathrm{O}_{3}$ oxide leads to intense spalling and peeling of the scales in the uncoated material. The results presented in this paper would be beneficial for improving properties of tools used in the die-casting industry.
\end{abstract}

\section{Introduction}

Molten aluminium corrosion is one of the major problems in the aluminium production industry since the molten aluminium reacts with nearly all metals and metal oxides [1]. These days the most frequently used die materials are hot work tool steels such as AISI H11 and AISI H13 grades [2]. Moreover, aluminum casting dies fail due to the following reasons: (a) fatigue cracking of the die surface induced by thermal cycling or heat chocking; (b) molten aluminum corrosion or soldering; (c) erosion wear by molten aluminum; or (d) catastrophic failure $[2,3]$. The corrosion wear originates by dissolution of the tool material into the liquid metal and the formation of intermetallic phases. There has been continuous research on surface modification of die steels as the die repair and replacement cost is expensive and unaffordable for many Die Casting industries.
The iron-based crucibles are subjected to rapid corrosion leading to the contamination of the molten aluminium when the protective coating fails [4]. In order to protect the crucibles and the cast dies against thermal cycling-induced fatigue cracking, there is a need to form a chemically stable and strong bonding layer on their surfaces. It is important to understand the nature of all types of environmental degradation of metals and alloys as vividly as possible. Preventive measures against metal loss and failures should be economically devised to ensure safety and reliability in the use of metallic components. At present, methods to minimize the extent of high temperature corrosion have been identified [5]. However, considerable research effort is needed for a quantitative evaluation of these methods under conditions of interest in the casting die materials.

A number of investigations on Physical Vapor Deposition (PVD) coating (TiN, TiAlN, and CrN) of die materials (AISI 
H10, H13, and H19) have been reported and the results show that these coatings provide good resistance to corrosion in molten aluminium $[6,7]$. In addition to PVD Coating, the Flame Spray Coating process is one of the most widely used technique to prepare composite structural parts to obtain required mechanical strength properties as well as inhibition of oxidation and other corrosive degradation processes. The main advantage of flame spray technique is that it enables a whole range of materials including metals and alloys to a great variety of substrate types and geometries. Due to significant improvements in the construction and technology of oxyacetylene torches, high particle velocities in the range of $200-300 \mathrm{~m} / \mathrm{s}$ can be obtained, which generate high combustion and particle temperatures $\left(2600^{\circ} \mathrm{C}\right)$ [8].

The adhesion and/or cohesion of thermally sprayed coatings is generally measured by the tensile test method (ASTM C633), which has certain drawbacks due to a complex experimental setup and necessity of glue with high-bond strength $[9,10]$. An alternative method known as scratch testing on the cross-section of the sample was proposed in the 1990s although it was never really developed [11, 12]. Moreover, scratch testing method is relatively easy to use especially in industrial areas or as a complement to tensile testing. The mechanism of scratch is suggested to correlate well with damage mechanism occurring at abrasive wear [13]. An appropriate interpretation of load versus acoustic activity at the test can also be useful to estimate the thin coating toughness [14].

EWAC 1001 coatings modified by the addition of $20 \%$ WC were proved [15] excellent candidates for providing protection against abrasive wear. Specifically, these coating materials often contain WC and CrC particles as per needs to improve the abrasive wear resistance. The major benefit in addition of high fraction of WC particles is the increase in hardness while chromium matrix provides the desired toughness $[16,17]$. It has also been reported that the hardness of Co base coating depends on microstructural parameters such as fraction of soft matrix and type, size, shape and fraction of carbide particles $[18,19]$. It is also widely known that EWAC 1006EE is a Co-Cr-W-Ni-C base surfacing alloy which can be easily deposited using lowcost flame-spraying method and is, therefore, of greater commercial importance for abrasive wear applications [15].

AISI H13 is a high-strength steel that is frequently employed in industry due to its extraordinary shock resistance. Thermal fatigue cracking is one of the most important lifelimiting tool failure mechanisms in aluminium and brass die casting. Thermal fatigue cracking results from the rapid alternations in die surface temperature, which may induce stresses high enough to impose an increment of plastic strain in the tool surface during each casting cycle leading to surface cracks. While the benefits of WC with EWAC 1001 to improve the wear resistance of tool steels are recognized [15], its cyclic air oxidation performance at elevated temperatures is not well established. Despite the importance of this tool material, to the best of the author's knowledge, the high temperature corrosion behavior of EWAC 1001-coated AISI H13 steel is not reported in the specialized literature.
TABLE 1: Chemical composition of EWAC 1001 alloy powders.

\begin{tabular}{lc}
\hline Coating powder & Composition (wt\%) \\
\hline EWAC 1001 & $\mathrm{Cr}(12), \mathrm{C}(2), \mathrm{Si}(5), \mathrm{B}(4), \mathrm{Fe}(4), \mathrm{Ni}(\mathrm{bal})$ \\
\hline
\end{tabular}

TABLE 2: Flame spray process parameters.

\begin{tabular}{llc}
\hline S. no. & Parameters & Quantity \\
\hline 1 & Cleaning of substrate using acetone & - \\
2 & The pressure of the oxygen & $3 \mathrm{kPa}$ \\
3 & The pressure of acetylene & $1.2 \mathrm{kPa}$ \\
4 & Torch angle with respect to plate & $60^{\circ}$ \\
5 & Distance of torch tip from the substrate & $20 \mathrm{~mm}$ \\
6 & Torch speed & $0.10 \mathrm{~m} / \mathrm{min}$ \\
7 & Preheat temperatures & $300^{\circ} \mathrm{C}$ \\
\hline
\end{tabular}

The scope of the present investigation is to explore the improvement of corrosion resistance of AISI H13 steels after EWAC 1001 coating by flame spray technique. The objective of the present research work is to characterize the EWAC 1001 and EWAC $1001+$ WC (20\%) flamesprayed coatings on the AISI H13 steel and to evaluate the oxidation behavior of coated and uncoated $\mathrm{H} 13$ steel in an air oxidation environment at $700^{\circ} \mathrm{C}$ under cyclic conditions. The characterizations of the coatings and corrosion products have been done using the combined techniques of optical microscopy, X-ray diffraction (XRD), and scanning electron microscopy/energy-dispersive analysis (SEM/EDAX).

\section{Experimentation}

AISI H13 steel with chemical composition weight percentage 0.4 C, $5.13 \mathrm{Cr}, 1.33 \mathrm{~V}, 1.00 \mathrm{Mo}, 1.00 \mathrm{Si}$, and remaining Fe was used as a substrate. The specimen size cut from steel plate is $\sim 20 \times 15 \times 5 \mathrm{~mm}^{3}$. These specimens were polished and grit blasted by sand blast (Grit 60) before coating. Commercial coating powder EWAC 1001 and modified EWAC 1001 by adding WC $(20 \%)$ were deposited by flame spraying process, and the chemical composition for these powders are shown in Table 1. The observation of the powders in Scanning Electron Microscope of powders (Figure 1) showed that the particles had a spherical morphology with dendritic structure. Moreover, the sizes of the larger particles were around $44 \mu \mathrm{m}$. In addition to that, there is no noticeable size difference between original and modified powders. During the coating process, roughly $228 \mu \mathrm{m}$ thick coatings were deposited by commercial flame spray apparatus. This process operates with oxygen-acetylene as input gases, and the spraying parameters are listed in Table 2. For facilitating the metallurgical examination, the specimens were sectioned, mounted, and polished after the deposition. In order to study the microstructure and porosity, the coated samples were examined under a metallurgical microscope. The porosity measurements were obtained using image analyzer (Material Pro 3.0), and the coatings were analyzed by SEM, EDAX, and XRD techniques for studying the phase composition. 


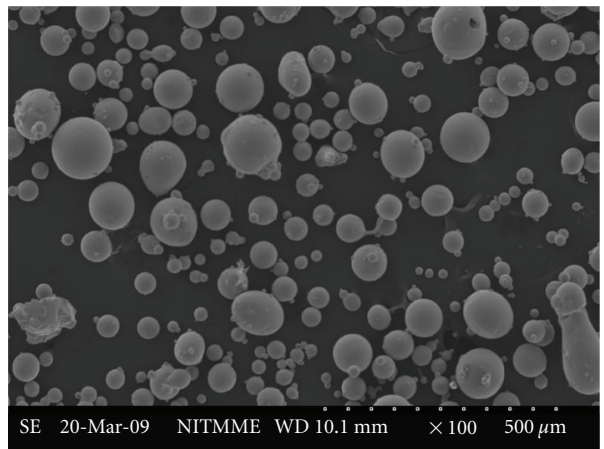

(a)

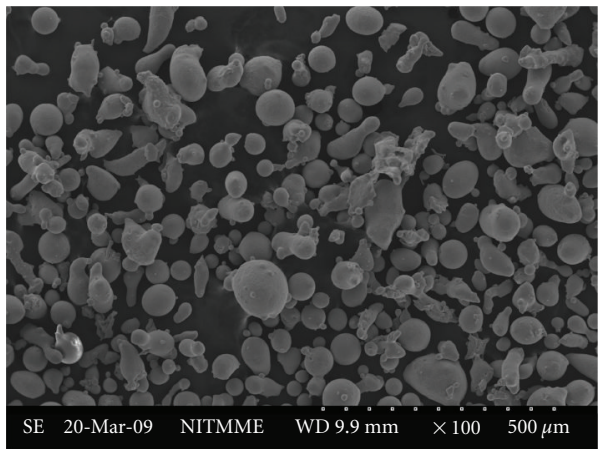

(b)

Figure 1: SEM of EWAC 1001 (a) and modified EWAC 1001 (b) powder.

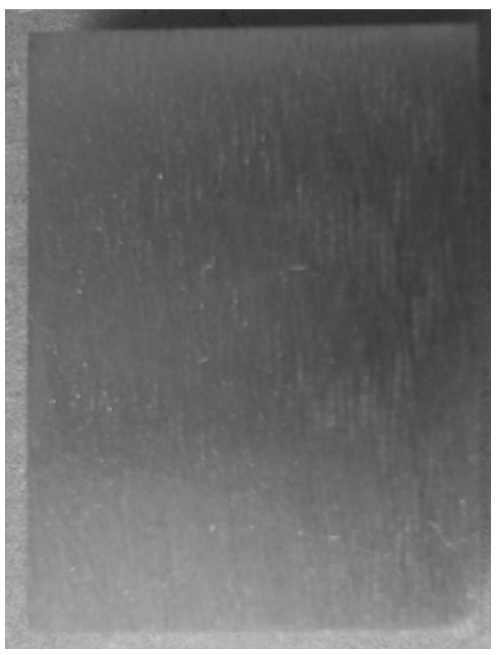

(a)

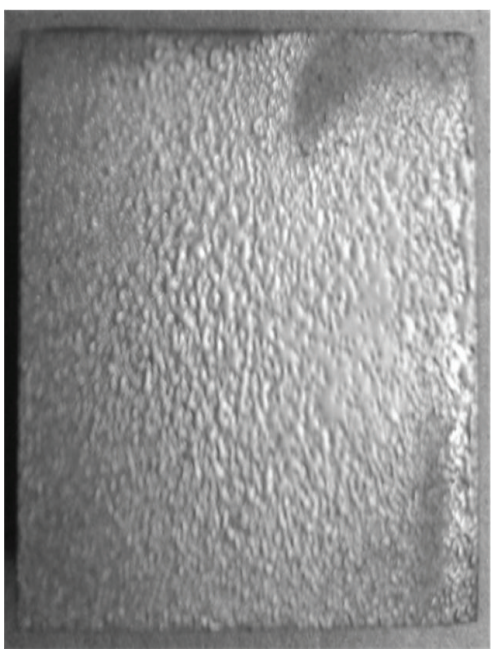

(b)

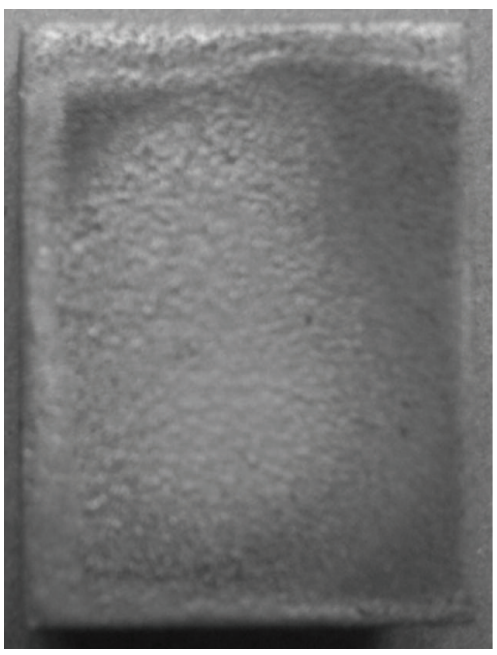

(c)

FIgURE 2: Photograph of substrate AISI H13 steel (a): EWAC 1001-coated AISI H13 (b) and EWAC 1001 + (20\%) WC-coated AISI H13 steel (c).

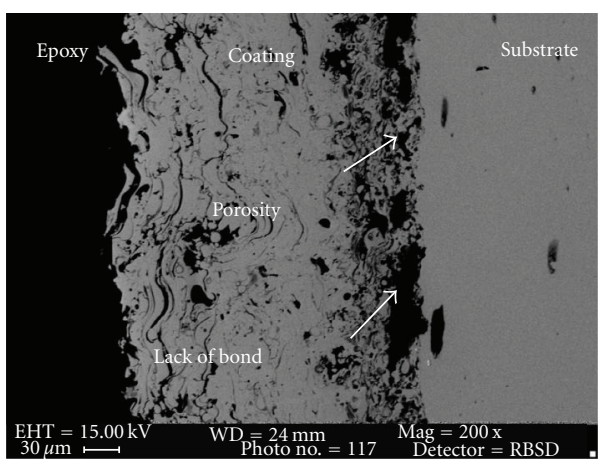

(a)

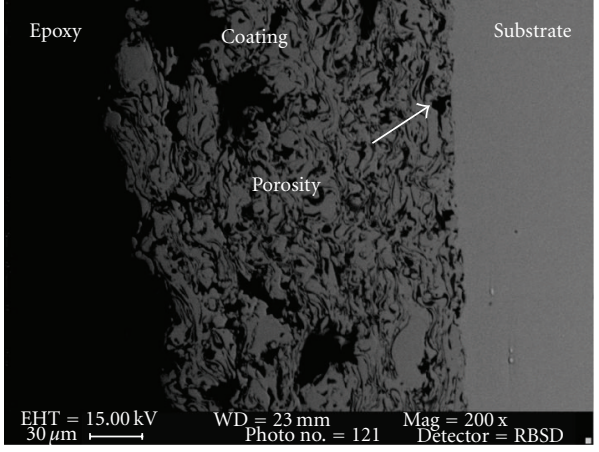

(b)

FIGURE 3: BSEI micrographs showing cross-sectional morphology of flame-sprayed coatings of EWAC 1001 (a) and modified EWAC 1001 by addition of 20\% WC (b) on AISI H13 steel. (Coating Thickness 200-228 ( $\mu \mathrm{m})$; Porosity $(2.88-4.42 \%)$ ). 
A microhardness tester (SMV-1000 series) was used to study the microhardness at cross-sections of the deposits with a load of $100 \mathrm{~g}$ for duration of 10 seconds. Scratch test was performed using a commercial microscratch tester (DUCOM, TR104, India) to evaluate the scratch resistance of the coatings. A spherical Rockwell C diamond stylus of $100 \mu \mathrm{m}$ radius was used to produce the scratch. The test was carried out under ramp loading mode with the load ranging from $20 \mathrm{~N}$ to $200 \mathrm{~N}$. The loading was varied in steps of $2 \mathrm{~N} / \mathrm{mm}$, and the stylus scanned the coating surface perpendicularly at a speed of $0.5 \mathrm{~mm} / \mathrm{s}$. The total length of the scratch scar was $10 \mathrm{~mm}$. The critical load was calculated from the plot by measuring the change in the slope of the traction forces.

Corrosion studies were performed on uncoated AISI H13 steel and that coated with modified EWAC 1001 powder. Cyclic air oxidation studies were performed for 50 cycles, with each cycle consisting of $1 \mathrm{~h}$ heating at $700^{\circ} \mathrm{C}$, followed by $20 \mathrm{~min}$ cooling at room temperature. The aim of cyclic loading is to create severe conditions for testing. These studies were performed for uncoated and coated samples for the purpose of comparison. The samples were mirrorpolished, down to $1 \mu \mathrm{m}$ alumina wheel cloth polishing before corrosion studies. Weight-change measurements were taken at the end of each cycle using an electronic balance (OhausAdventure Pro AVG264C) with a sensitivity of $1 \mathrm{mg}$. At the time of weighing, the spalled scales were also included to determine the total rate of corrosion. Efforts were made to formulate the kinetics of corrosion. The surface of the corroded specimens was visually observed to record color, spalling, and peeling of scale during cyclic corrosion. The samples after the corrosion run were examined by SEM, EDAX, and XRD for surface analysis. The samples were then cut and mounted for cross-sectional analysis by EDAX and EPMA.

\section{Result and Discussion}

EWAC 1001 and modified EWAC 1001 coatings have been formulated successfully by flame spray technique on AISI H13 steels using Oxygen-acetylene gas. The photographs of coated and uncoated samples are shown in Figure 2. The thickness of coating was measured with micrograph which is in the range of $200-228 \mu \mathrm{m}$ shown in Figure 3. The porosity for as-sprayed EWAC 1001 coating is in the range of $2.88-4.42 \%$. The porosity values of sprayed EWAC 1001 coatings are within the range of porosity values observed for flame spray using propane fuel coating by Wang and Lee [20].

The critical hardness values of the substrate steels were found to be in the range of 380-490 Hv. The microhardness of the EWAC 1001 coatings was measured to be around $890 \mathrm{Hv}$ and is almost identical to the findings of Scrivani et al. [21] which is evident from the hardness profiles presented in Figure 4. The hardness value for EWAC $1001+$ WC (20\%) is around $965 \mathrm{Hv}$, which is higher than EWAC 1001 coatings. This being mainly due to higher concentration of tungsten monocarbide crystals (WC) well dispersed in the continuous

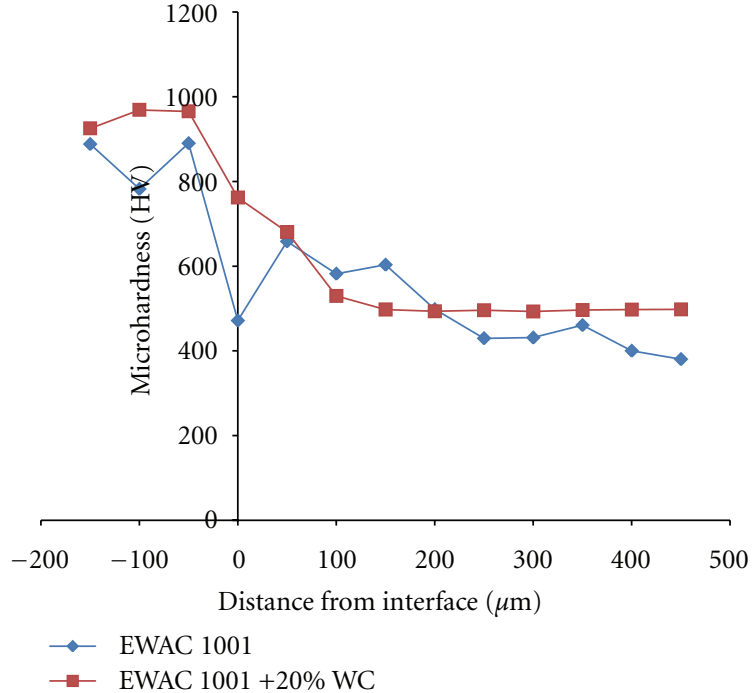

Figure 4: Microhardness profiles of EWAC 1001 and EWAC $1001+$ WC (20\%) coating on AISI H13 steel along the cross-section.

Ni matrix. X-ray diffraction analysis further confirmed the presence of WC in this coating.

Further, the scratch resistance of the coatings was tested by measuring the critical load required to remove the coating from the substrate using scratch tester. The highest critical loads $149 \mathrm{~N}$ and $170 \mathrm{~N}$ were obtained for the EWAC 1001 and modified EWAC 1001 by addition of 20\% WC, respectively, indicating that WC has enhanced scratch resistance. Micrographs of EWAC 1001 of scratch tracks are presented in Figure 5(a). The scratch groove of EWAC 1001 coating was much deeper with a larger width and minute cracks and a small deformation. In the case of modified EWAC 1001 coating, slight damages were noticed around the grooves indicating that the cause of failure is due to ductile fracture Figure 5(b). The poor scratch resistance of EWAC 1001 coating is mainly due to the presence of weakly consolidated splats and pores, whereas the higher scratch resistance of modified EWAC 1001 coating is attributed to the presence of melted splats. On the other hand, the highest scratch resistance of modified EWAC 1001 coating is due to the higher adhesion, hardness, and less porosity of the coating.

In modified EWAC 1001 flame-sprayed AISI H13 steel, the morphological investigations using SEM has revealed irregular coarse splats with distinct boundaries as evident in Figure 6. Moreover, it was observed that the distribution of secondary phase was in the form of globules with presence of some oxide stringers and open pores. SEM/EDAX analysis indicates a matrix which contains $69.52 \% \mathrm{Ni}, 26.15 \% \mathrm{Cr}$, and $4.96 \% \mathrm{~W}$ (Figure 7). From the SEM micrographs, it was observed that there are areas depleted of $\mathrm{W}$ in the matrix, and there are black areas which are rich in Ni. There is presence of Ni-rich and chromium-depleted nodules in the matrix.

The photographs of coated and uncoated samples after corrosion treatment are shown in Figure 8. Oxidation rate in 


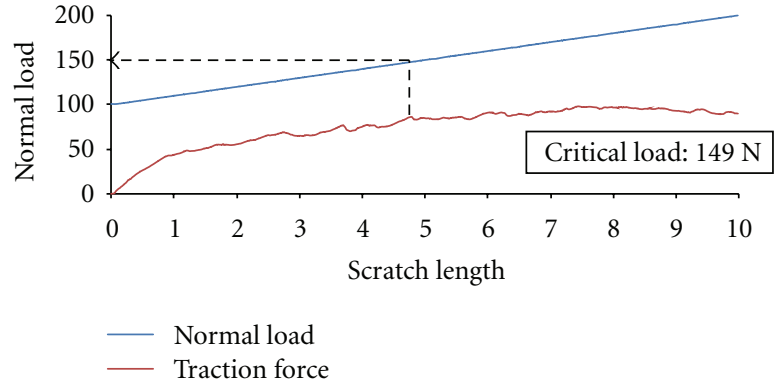

(i)

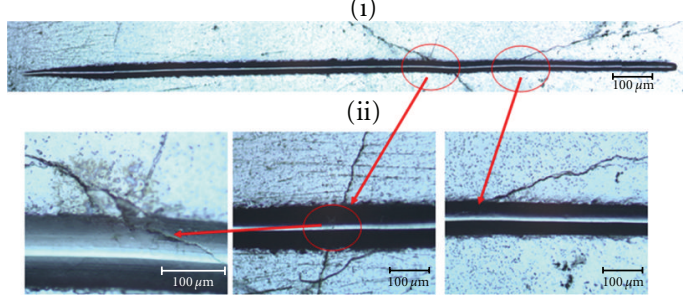

(a)

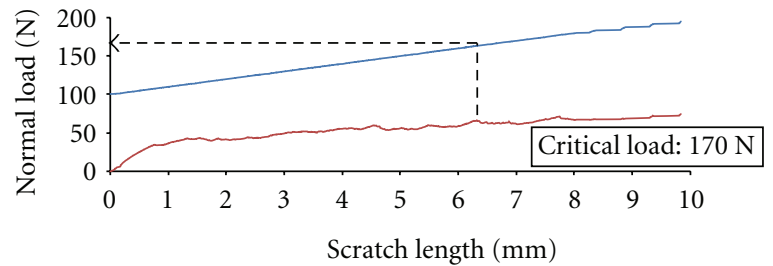

— Normal load

_ Traction force

(i)

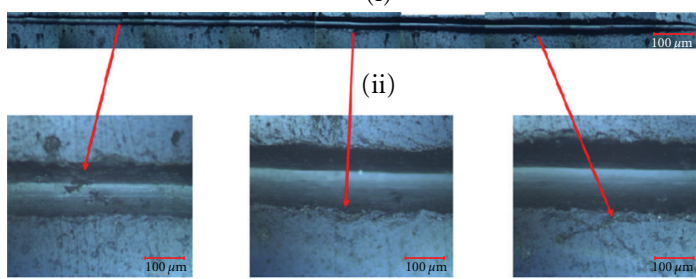

(b)

Figure 5: (a) Micrographs of EWAC 1001 of scratch tracks and typical scratch curve. (i) Scratch curve and (ii) scratch track. (b) Micrographs of EWAC $1001+$ WC (20\%) of scratch tracks and typical scratch curve. (i) Scratch curve and (ii) scratch track.

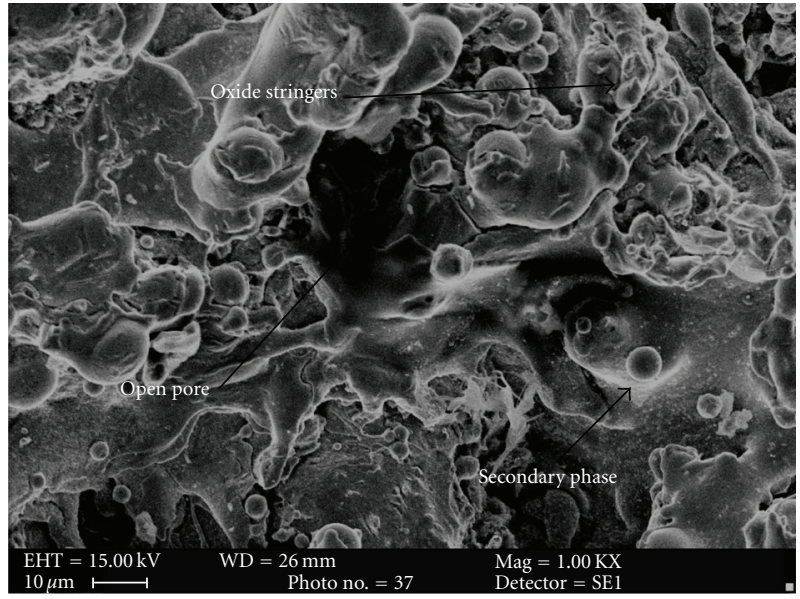

FIGURE 6: SEM micrographs showing surface morphology of flamesprayed EWAC $1001+$ WC (20\%) coating on H13 steel.

terms of weight gain/unit area for the bared AISI H13 steel and modified EWAC 1001 is presented in Figure 9, where the protective behavior of modified EWAC 1001 coating is clearly visible. Notably, appreciable increase in weight gain is observed after air oxidation at $700^{\circ} \mathrm{C}$ in modified EWAC 1001 coating. Nevertheless, bare AISI H13 steel has suffered accelerated rate of corrosion, which is almost thrice the oxidation rate of coated AISI H13 steel. The parabolic rate constants $\left(K_{p}\right)$ (Figure 10) for bare and EWAC-coated AISI H13 steels exposed under air oxidation were found out by slope of the linear regression fitted line (cumulative weight gain/area) $)^{2}$ and are calculated as 0.381 and $0.138 K_{p} \times 10^{-6}$ $\left(\mathrm{g}^{2} \mathrm{~cm}^{-4} \mathrm{~S}^{-1}\right)$, respectively. Since the $K_{p}$ values of the coated

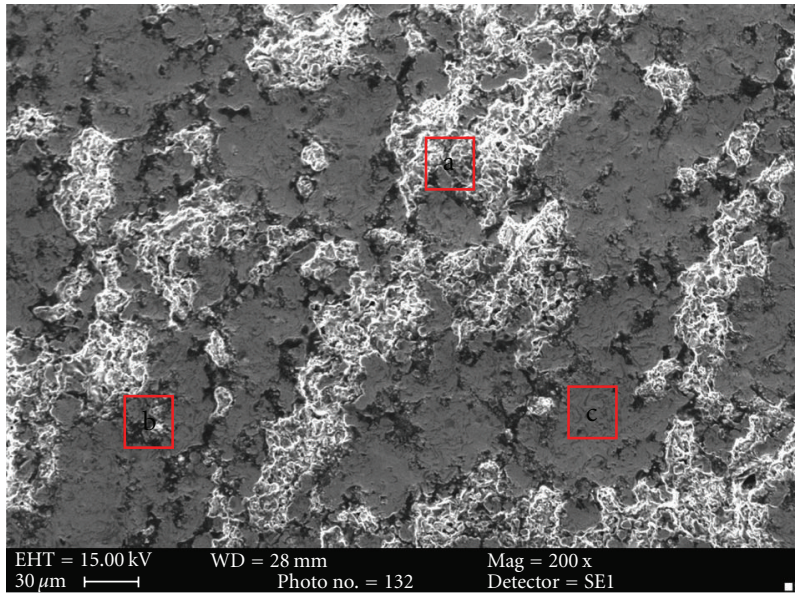

FIGURE 7: SEM/EDAX analysis of the flame-sprayed coating showing elemental composition (\%) at selected areas. (a) $54.21 \% \mathrm{Ni}$, $28.39 \% \mathrm{Cr}, 15.76 \% \mathrm{~W}$; (b) $49.13 \% \mathrm{Ni}, 35.9 \% \mathrm{Cr}, 8.01 \% \mathrm{~W}$; (c) $69.52 \% \mathrm{Ni}, 26.15 \% \mathrm{Cr}, 4.96 \% \mathrm{~W}$.

specimen are less, it is observed that modified EWAC 1001 coating has behaved well during air oxidation. Similar observation has been made by Schmidt and Ferriss [22] showing outstanding behaviour of cobalt base Tribaloy in corrosion tests indicating low or moderate weight loss. Natesan [23] has also reported the superior corrosion resistance of Stellite $6 \mathrm{~B}$ alloy in mixed gas environment.

The XRD patterns for the corroded surfaces of uncoated and coated AISI H13 steel exposed to air oxidation environment at $700^{\circ} \mathrm{C}$ after 50 cycles are shown in Figure 11. In case of uncoated samples, the main phases identified are $\mathrm{Fe}_{2} \mathrm{O}_{3}$, 


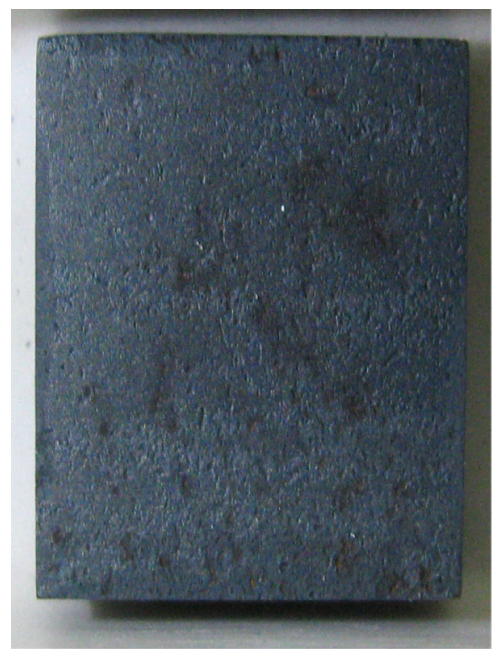

(a)

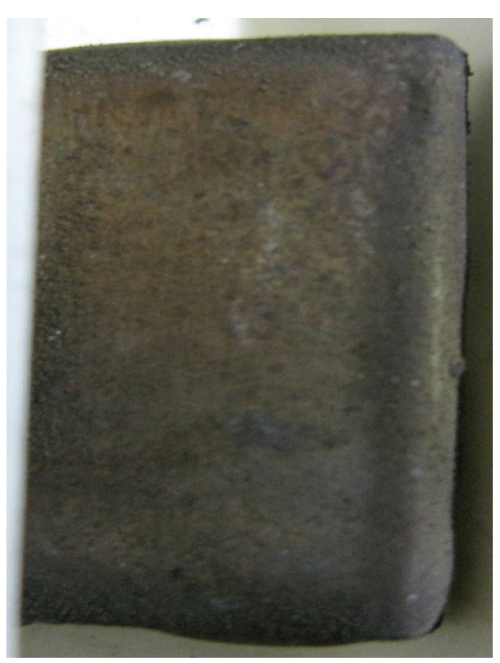

(b)

FIGURE 8: Photograph of air-oxidized substrate AISI H13 steel: (a) and EWAC $1001+(20 \%)$ WC-coated AISI H13 steel (b) at $700^{\circ} \mathrm{C}$ after 50 cycles.

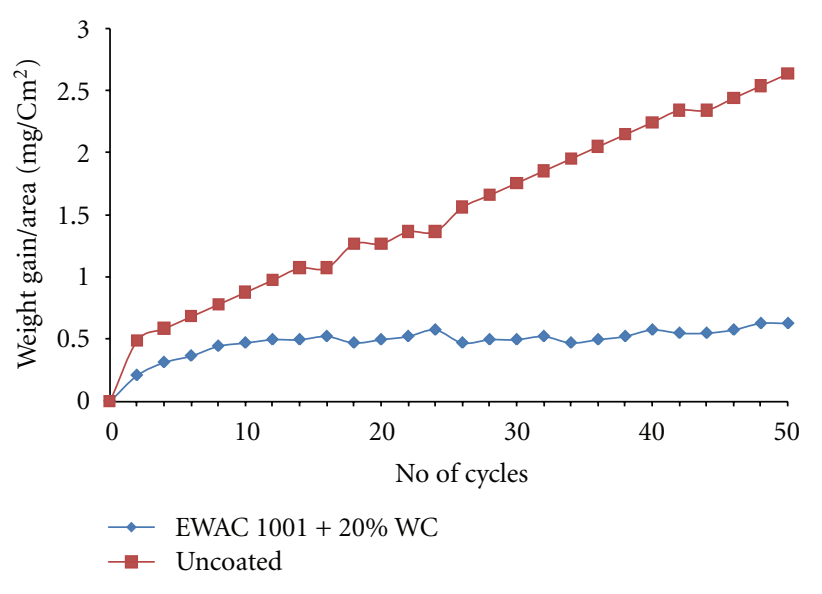

Figure 9: Weight gain versus time plot for bare and EWAC $1001+$ (20\%) WC-coated $\mathrm{H} 13$ steels exposed to air at $700^{\circ} \mathrm{C}$ for 50 cycles.

$\mathrm{Cr}_{2} \mathrm{O}_{3}, \mathrm{MoO}_{2}$, and $\mathrm{SiO}_{2}$, whereas in case of EWAC 1001, additional phases $\mathrm{NiO}, \mathrm{NiCr}_{2} \mathrm{O}_{4}, \mathrm{Cr}_{3} \mathrm{Ni}_{2}, \mathrm{FeCr}, \mathrm{FeNi}$, and $\mathrm{FeNi}_{3}$ are revealed on the scale. In XRD studies on hot corroded EWAC $1001+20 \%$ WC samples, the presence of WC along with small amounts of tungsten hemicarbide $\mathrm{W}_{2} \mathrm{C}$ is revealed. This result is attributed to higher flame velocity and flame temperature in flame spray process. These conditions have successfully limited the decomposition process during coating. Similar peaks have also been observed by Stewart et al. [24] and Sahraoui et al. [25].

SEM/EDAX analysis for bare AISI H13 steel after air oxidation shows the presence of distorted grains, and the presence of iron oxide in the surface scale is observed (Figure 12(a)). Further, diffusion of iron from the substrates and oxidation on the top layer of scale had been indicated. The scale morphology for EWAC $1001+20 \%$ WC-coated

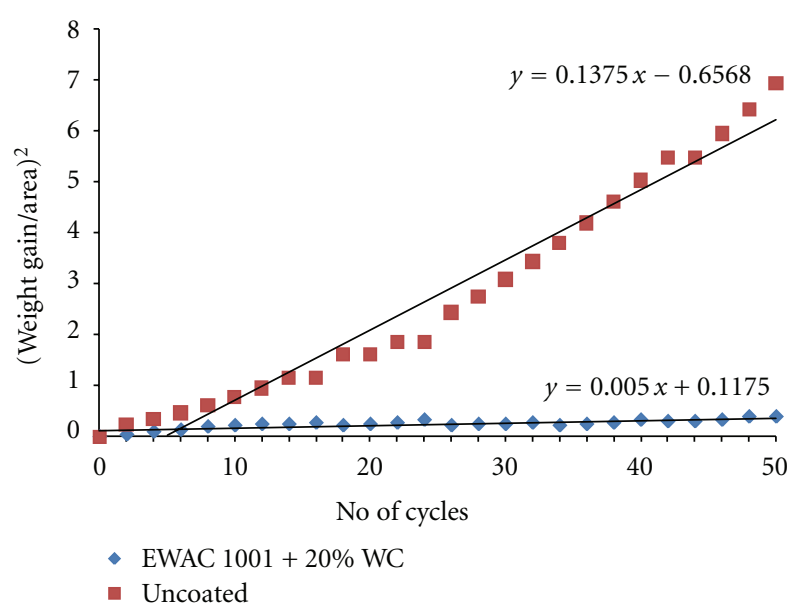

FIGURE 10: (Weight gain/area) ${ }^{2}$ versus number of cycles plot for bared and EWAC $1001+(20 \%)$ WC-coated H13 steel exposed to air at $700^{\circ} \mathrm{C}$ for 50 cycles.

steel after oxidation in air at $700^{\circ} \mathrm{C}$ is observed as a two-phase structure (Figure 12(b)). The EDAX analysis for coated AISI $\mathrm{H} 13$ steel indicates that top scale consists of oxides of $\mathrm{Ni}$ and $\mathrm{Cr}$, and the spalled region is rich in $\mathrm{Ni}$. The internal oxidation in case of plasma spray coatings had also been reported by Niranatlumpong et al. [26] and Evans and Taylor [27] and had been attributed to porosity. The cracking of oxide scale as observed in the present study in air at $700^{\circ} \mathrm{C}$ might be attributed to the different composition of coatings, substrate, and oxides formed. As a result of this different composition, the difference in thermal expansion coefficients inevitably results in thermal-stresses as suggested by Rapp et al. [28, 29] and Liu et al. [30]. Further, the small cracks developed in the scale and coatings due to mechanical and thermal shock 


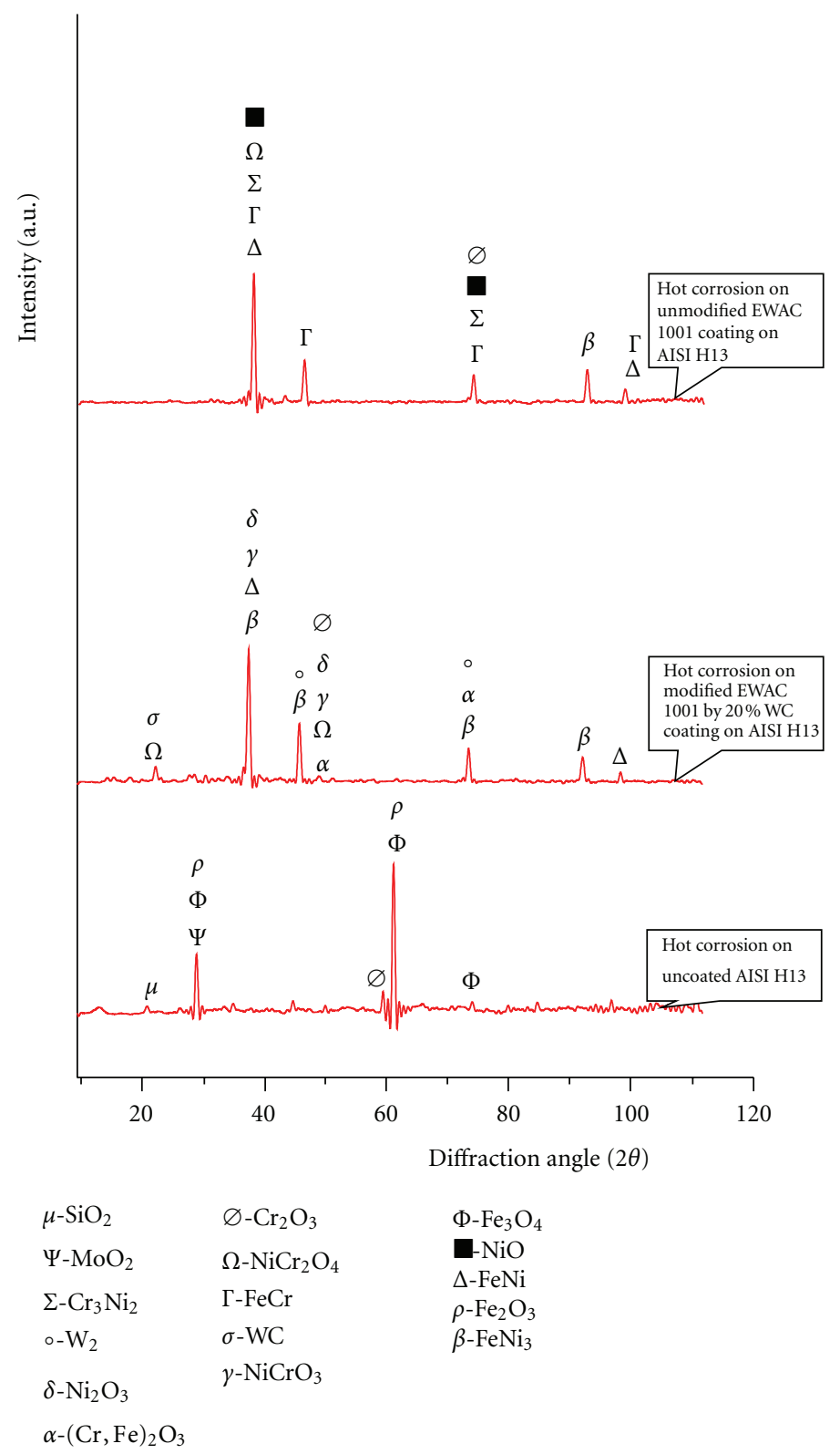

FIGURE 11: X-Ray diffraction patterns for hot corroded uncoated and coated AWAC 1001 and EWAC 1001 + WC (20\%) AISI H13 steel.

are believed to be sealed by the oxide protrusion from the beneath. These results in sealing of the cracks in case of coated specimens during corrosion which tends to eliminate any significant increase in weight gain.

EDAX analysis on bare AISI $\mathrm{H} 13$ confirmed the presence of $\mathrm{Fe}_{2} \mathrm{O}_{3}$ on upper scale subsequently followed by $\mathrm{Fe}_{2} \mathrm{O}_{3}$ and $\mathrm{Cr}_{2} \mathrm{O}_{3}$ on the subscale which is found to be coexisting. This can be attributed to depletion of iron to form oxides in the upper scale, thereby leaving behind chromium-rich pockets, which further get oxidised to form oxides of chromium in the inner scale. Similar observations can be found in hot corrosion studies of low alloy steels [31]. The EDAX analysis for EWAC $1001+20 \%$ WC-coated AISI H13, the spinels of nickel and chromium along with chromium oxide in the top scale might has also contributed to the protection of the base steel. The oxides and spinels of nickel and chromium, in the reaction layer between substrate and coating layer might be responsible for blocking the transport of species through it. The oxides of nickel and some amount of chromium may also have played their role for the reduction in total weight gain values as compared to the uncoated steel.

Niranatlumpong et al. [26] also suggested increase in the pore size of $\mathrm{Ni}$ and $\mathrm{Cr}$ in the scale with increase in exposure time. This allows the degrading species to penetrate through the coating thereby resulting in the oxidation of substrate steels. In case of EWAC 1001 coating, the beneficial effect may be due to the formation of $\mathrm{NiCr}_{2} \mathrm{O}_{4}$ spinel and presence of continuous $\mathrm{Cr}_{2} \mathrm{O}_{3}$ layer at scale-substrate interface. Luthra [32] has proposed that $\mathrm{NiCr}_{2} \mathrm{O}_{4}$ spinel obstructs the diffusion activities through the nickel oxide $(\mathrm{NiO})$ by suppressing 


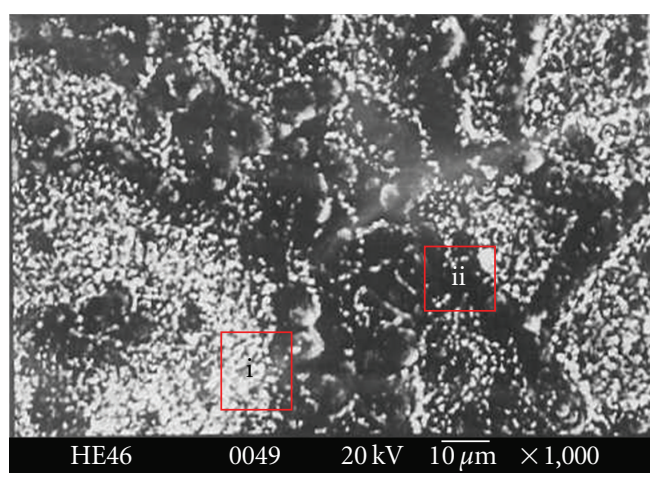

(a)

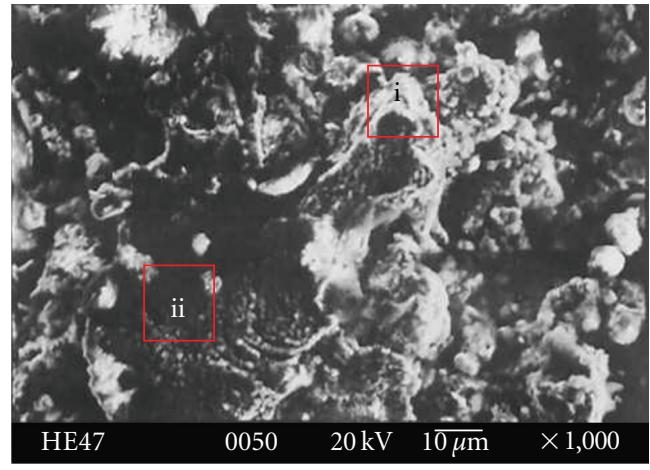

(b)

FIGURE 12: (a) Surface scale morphology and EDAX analysis for the uncoated AISI H13 steel subjected to cyclic oxidation in air at $700^{\circ} \mathrm{C}$ for 50 cycles: (i) $97.59 \% \mathrm{Fe}_{2} \mathrm{O}_{3}, 02.36 \% \mathrm{MnO}$ and (ii) $82.55 \% \mathrm{Fe}_{2} \mathrm{O}_{3}, 17.54 \% \mathrm{MnO}$. (b) Surface scale morphology and EDAX analysis for the EWAC $1001+$ WC $(20 \%)$ coated $\mathrm{H} 13$ steel subjected to cyclic oxidation in air at $700^{\circ} \mathrm{C}$ for 50 cycles: (i) $32 \% \mathrm{Cr}_{2} \mathrm{O}_{3}, 64 \% \mathrm{NiO}, 1.5 \% \mathrm{SiO}{ }_{2}$ and (ii) $19 \% \mathrm{NiO}, 76 \% \mathrm{Cr}_{2} \mathrm{O}_{3}, 03 \% \mathrm{SiO}_{2}$.

TABLE 3: The cumulative properties of with and without coated AISI H13 steel.

\begin{tabular}{|c|c|c|c|c|c|}
\hline Specimen & XRD & $\begin{array}{c}\text { Hard. At } \\
\text { coating }(\mathrm{HV})\end{array}$ & $\begin{array}{c}\text { Scratch } \\
\text { resistance: } \\
\text { Critical Load }(\mathrm{N})\end{array}$ & $\begin{array}{l}\text { Corrosion rate [parabolic } \\
\left.\text { rate constants }\left(K_{p}\right)\right] \\
\left(\mathrm{g}^{2} \mathrm{~cm}^{-4} \mathrm{~S}^{-1}\right) \times 10^{-6}\end{array}$ & Remark \\
\hline Substrate AISI H13 & $\begin{array}{l}\mathrm{Fe}_{2} \mathrm{O}_{3}, \mathrm{Cr}_{2} \mathrm{O}_{3}, \mathrm{MoO}_{2} \\
\text { and } \mathrm{SiO}_{2}\end{array}$ & $380-490$ & - & 0.381 & $\begin{array}{l}\text { Corrosion rate is three } \\
\text { times more than EWAC } \\
1001+(20 \%) \text { WC-coated } \\
\text { AISI H13 steel. During } \\
\text { corrosion test, intense } \\
\text { spalling and peeling off } \\
\text { scale was noticed }\end{array}$ \\
\hline $\begin{array}{l}\text { EWAC 1001-coated } \\
\text { AISI H13 }\end{array}$ & $\begin{array}{l}\mathrm{NiO}, \mathrm{NiCr}_{2} \mathrm{O}_{4}, \\
\mathrm{Cr}_{3} \mathrm{Ni}_{2}, \mathrm{FeCr}, \mathrm{FeNi}, \\
\mathrm{Cr}_{2} \mathrm{O}_{3}, \mathrm{FeNi}_{3}\end{array}$ & $780-890$ & 149 & - & Poor scratch resistance \\
\hline $\begin{array}{l}\text { EWAC } 1001+(20 \%) \\
\text { WC-coated AISI H13 }\end{array}$ & $\begin{array}{l}\mathrm{NiCr}_{2} \mathrm{O}_{4}, \mathrm{WC}, \mathrm{Ni}_{2} \mathrm{O}_{3}, \\
\mathrm{NiCrO}_{3}, \mathrm{FeNi}, \mathrm{FeNi}_{3}, \\
\mathrm{~W}_{2} \mathrm{C}, \mathrm{Cr}_{2} \mathrm{O}_{3}, \\
(\mathrm{Cr}, \mathrm{Fe})_{2} \mathrm{O}_{3}\end{array}$ & $925-965$ & 170 & 0.138 & $\begin{array}{l}\text { Spinels of } \mathrm{NiCr}_{2} \mathrm{O}_{4}, \mathrm{Cr}_{2} \mathrm{O}_{3} \\
\text { and NiO leads to increase } \\
\text { corrosion resistance. } \\
\text { Increased scratch resistance } \\
\text { due to addition of WC }\end{array}$ \\
\hline
\end{tabular}

the further formation of $\mathrm{NiO}$. The presence of continuous chromium band as well as the spinels is perhaps contributing to better oxidation resistance as they do not allow the transport of reacting species through them.

\section{Conclusion}

In the present investigation, the effect of flame spray coating on high temperature corrosion in air oxidation environment at $700^{\circ} \mathrm{C}$ has been studied. The cumulative properties of coated and uncoated AISI H13 steel are shown in Table 3 and the conclusions are as follows.

(a) Flame spray with oxy-acetylene as fuel gas has successfully been used to spray EWAC 1001 coatings on AISI H13 steel in the thickness range of $220-228 \mu \mathrm{m}$.

(b) The coating of EWAC $1001+\mathrm{WC}(20 \%)$ shows the best quality in terms of hardness, porosity, scratch, and high-temperature corrosion properties as compared to EWAC 1001.

(c) Microhardness measurement through the crosssection of coating showed that the both coatings have slightly higher hardness as compared to the substrate material.

(d) The scratch method can reveal substantial information about the quality of the coating and its scratch resistance properties. Higher critical load was noticed on EWAC $1001+(20 \%)$ WC-coating as compared to EWAC1001-coated AISI H13 steel.

(e) The weight gain of the coated and uncoated specimens follows a parabolic law during air oxidation at $700^{\circ} \mathrm{C}$, and the parabolic rate constant $\left(K_{p}\right)$ of uncoated specimen is almost thrice the oxidation rate of coated AISI H13 steel. 
(f) The uncoated substrate steel showed intense spalling, peeling off scale and weight gain was enormous during high temperature air oxidation studies at $700^{\circ} \mathrm{C}$. Moreover, $\mathrm{Fe}_{2} \mathrm{O}_{3}$ was identified as the major phase by $\mathrm{XRD}$ and EDAX analysis in the scale of uncoated AISI H13 steel.

(g) The presence of $\mathrm{NiCr}_{2} \mathrm{O}_{4}, \mathrm{Cr}_{2} \mathrm{O}_{3}$, and $\mathrm{NiO}$ has contributed to increase the oxidation resistance of EWAC $1001+(20 \%)$ WC-coated specimen.

(h) The flame spray modified EWAC 1001 coating confirmed the enhancement of mechanical and high temperature corrosion properties.

(i) AISI H13 steel could be coated by EWAC $1001+$ WC (20\%) using flame spray technique to enhance the corrosion resistance at cyclic air oxidation environment at $700^{\circ} \mathrm{C}$.

\section{References}

[1] D. Lou, O. M. Akselsen, M. I. Onsøien, J. K. Solberg, and J. Berget, "Surface modification of steel and cast iron to improve corrosion resistance in molten aluminium," Surface and Coatings Technology, vol. 200, no. 18-19, pp. 5282-5288, 2006.

[2] A. Persson, J. Bergström, C. Burman, and S. Hogmark, "Influence of deposition temperature and time during PVD coating of CrN on corrosive wear in liquid aluminium," Surface and Coatings Technology, vol. 146-147, pp. 42-47, 2001.

[3] Y. Wang, "A study of PVD coatings and die materials for extended die-casting die life," Surface and Coatings Technology, vol. 94-95, pp. 60-63, 1997.

[4] D. Wang, Z. Shi, and L. Zou, "A liquid aluminum corrosion resistance surface on steel substrate," Applied Surface Science, vol. 214, no. 1-4, pp. 304-311, 2003.

[5] U. K. Chatterjee, S. K. Bose, and S. K. Roy, Environmental Degradation of Metals, vol. 270, Marcel Dekker, New York, NY, USA, 2001.

[6] Y. Wang, "A study of PVD coatings and die materials for extended die-casting die life," Surface and Coatings Technology, vol. 94-95, pp. 60-63, 1997.

[7] M. Sundqvist and S. Hogmark, "Effects of liquid aluminium on hot-work tool steel," Tribology International, vol. 26, no. 2, pp. 129-134, 1993.

[8] D. E. Crawmer, Handbook of Thermal Spray Technology, 2004.

[9] ASTM C633-79, Standard Method of Test for Adhesion or Cohesive Strength of Flame-Sprayed Coatings, ASTM International, 1979.

[10] C. Lyphout, P. Nylén, and J. Wigren, "Global coating solutions," in Proceedings of the International Thermal Spray Conference, p. 588, ASM International, Materlas Park, Ohio, USA, 2007.

[11] E. Lopez, F. Beltzung, and G. Zambelli, "Fracture toughness measurement of plasma sprayed ceramic coatings," Journal of Materials Science Letters, vol. 8, pp. 346-353, 1989.

[12] L. C. Erickson, R. Westergård, U. Wiklund, N. Axén, H. M. Hawthorne, and S. Hogmark, "Cohesion in plasma-sprayed coatings - a comparison between evaluation methods," Wear, vol. 214, no. 1, pp. 30-37, 1998.

[13] S. J. Bull, "Can scratch testing be used as a model for the abrasive wear of hard coatings?" Wear, vol. 233-235, pp. 412-423, 1999.
[14] S. Zhang, D. Sun, Y. Fu, and H. Du, "Toughness measurement of thin films: a critical review," Surface and Coatings Technology, vol. 198, no. 1-3, pp. 74-84, 2005.

[15] S. Harsha, D. K. Dwivedi, and A. Agrawal, "Influence of WC addition in Co-Cr-W-Ni-C flame sprayed coatings on microstructure, microhardness and wear behaviour," Surface and Coatings Technology, vol. 201, no. 12, pp. 5766-5775, 2007.

[16] T. T. Wong, G. Y. Liang, B. L. He, and C. H. Woo, "Wear resistance of laser-clad Ni-Cr-B-Si alloy on aluminium alloy," Journal of Materials Processing Technology, vol. 100, no. 1, pp. 142-146, 2000.

[17] J. Rodríguez, A. Martín, R. Fernández, and J. E. Fernández, "An experimental study of the wear performance of NiCrBSi thermal spray coatings," Wear, vol. 255, no. 7-12, pp. 950-955, 2003.

[18] H. Skulev, S. Malinov, W. Sha, and P. A. M. Basheer, "Microstructural and mechanical properties of nickel-base plasma sprayed coatings on steel and cast iron substrates," Surface and Coatings Technology, vol. 197, no. 2-3, pp. 177-184, 2005.

[19] H. Skulev, S. Malinov, P. A. M. Basheer, and W. Sha, "Modifications of phases, microstructure and hardness of Ni-based alloy plasma coatings due to thermal treatment," Surface and Coatings Technology, vol. 185, no. 1, pp. 18-29, 2004.

[20] B. Q. Wang and S. W. Lee, "Elevated temperature erosion of several thermal-sprayed coatings under the simulated erosion conditions of in-bed tubes in a fluidized bed combustor," Wear, vol. 203-204, pp. 580-587, 1997.

[21] A. Scrivani, S. Ianelli, A. Rossi, R. Groppetti, F. Casadei, and G. Rizzi, "A contribution to the surface analysis and characterisation of HVOF coatings for petrochemical application," Wear, vol. 250-251, no. 1, pp. 107-113, 2001.

[22] R. D. Schmidt and D. P. Ferriss, "New materials resistant to wear and corrosion to $1000^{\circ}$ C," Wear, vol. 32, no. 3, pp. 279 289, 1975.

[23] K. Natesan, "Corrosion-erosion behavior of materials in a coal-gasification environment," in Proceedings of the Symposium Corrosion-Erosion Behavior of Materials, Fall Meeting of TMS-AIME, K. Natesan, Ed., p. 1, AIME, New York, NY, USA, 1987.

[24] D. A. Stewart, P. H. Shipway, and D. G. McCartney, "Abrasive wear behaviour of conventional and nanocomposite HVOFsprayed WC-Co coatings," Wear, vol. 225-229, no. II, pp. 789$798,1999$.

[25] T. Sahraoui, N. E. Fenineche, G. Montavon, and C. Coddet, "Structure and wear behaviour of $\mathrm{HVOF}$ sprayed $\mathrm{Cr} 3 \mathrm{C} 2-\mathrm{NiCr}$ and WC-Co coatings," Materials and Design, vol. 24, no. 5, pp. 309-313, 2003.

[26] P. Niranatlumpong, C. B. Ponton, and H. E. Evans, "Failure of protective oxides on plasma-sprayed NiCrAlY overlay coatings," Oxidation of Metals, vol. 53, no. 3, pp. 241-258, 2000.

[27] H. E. Evans and M. P. Taylor, "Diffusioncells and chemical failure of MCrAlY bond coats in thermal-barrier coating systems," Oxidation of Metals, vol. 55, no. 1-2, pp. 17-34, 2001.

[28] R. A. Rapp, J. H. Devan, D. L. Douglass, P. C. Nordine, F. S. Pettit, and D. P. Whittle, "High temperature corrosion in energy systems," Materials Science and Engineering, vol. 50, no. 1, pp. $1-17,1981$.

[29] R. A. Rapp and K. S. Goto, "The hot corrosion of metals by molten salts," in Proceedings of the Symposium on Molten Salts, J. Braunstein and J. R. Selman, Eds., p. 159, The Electrochemical Society, Pennington, NJ, USA, 1981.

[30] P. S. Liu, K. M. Liang, H. Y. Zhou et al., "Cyclic oxidation behavior of aluminide coatings on the Co-base superalloy 
DZ4OM," Surface and Coatings Technology, vol. 145, no. 1-3, pp. 75-79, 2001.

[31] S. E. Sadique, A. H. Mollah, M. S. Islam, M. M. Ali, M. H. H. Megat, and S. Basri, "High-temperature oxidation behavior of iron-chromium-aluminum alloys," Oxidation of Metals, vol. 54, no. 5-6, pp. 385-400, 2000.

[32] K. L. Luthra, "Kinetics of the low temperature hot corrosion of Co-Cr-Al alloys," Journal of the Electrochemical Society, vol. 132, no. 6, pp. 1293-1298, 1985. 

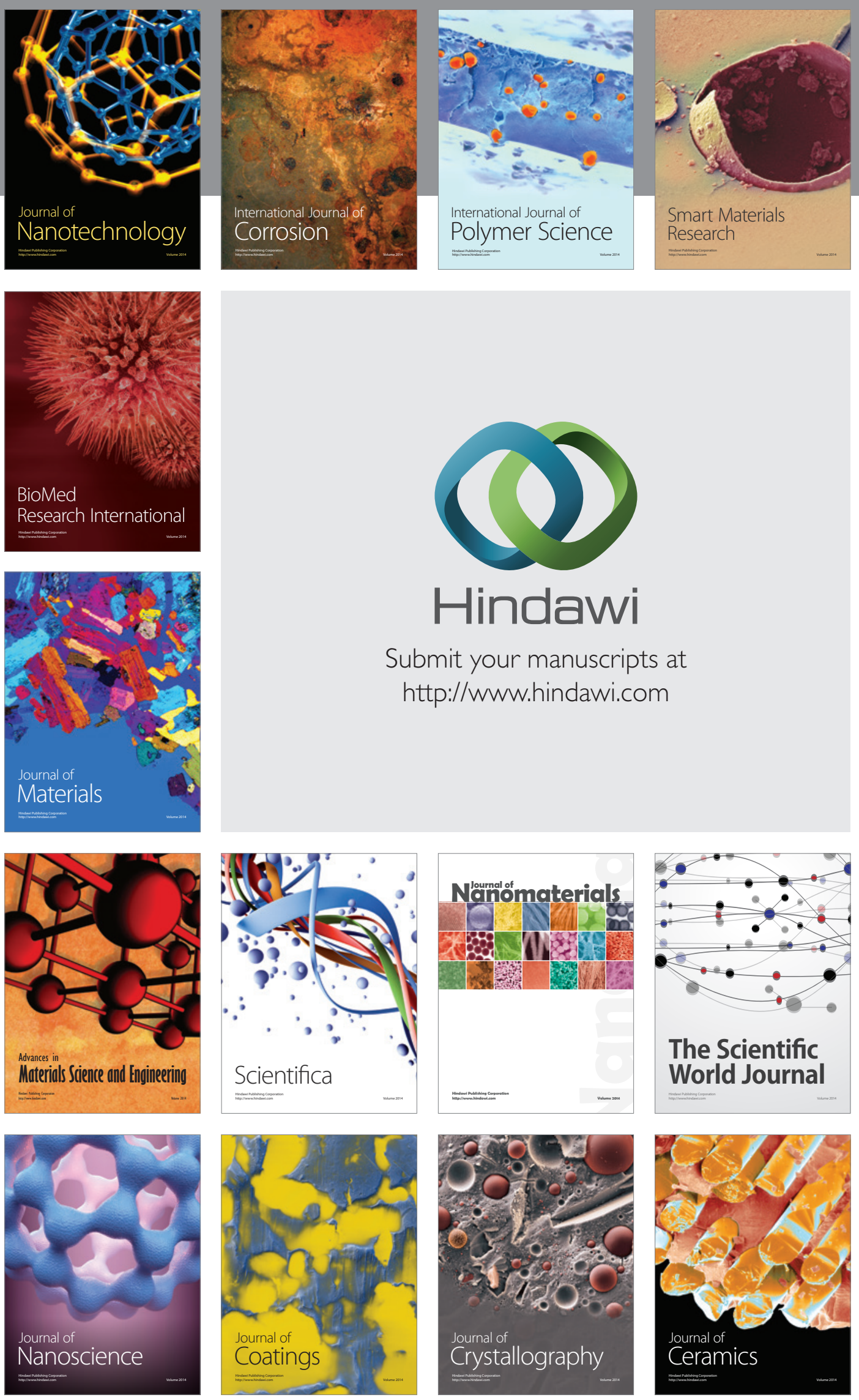

The Scientific World Journal

Submit your manuscripts at

http://www.hindawi.com

\section{World Journal}

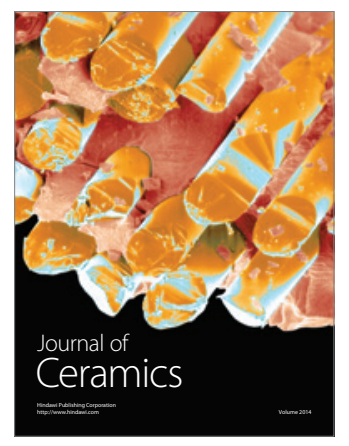

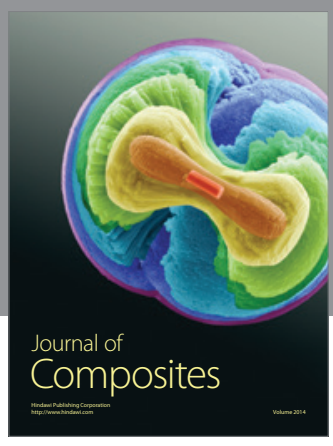
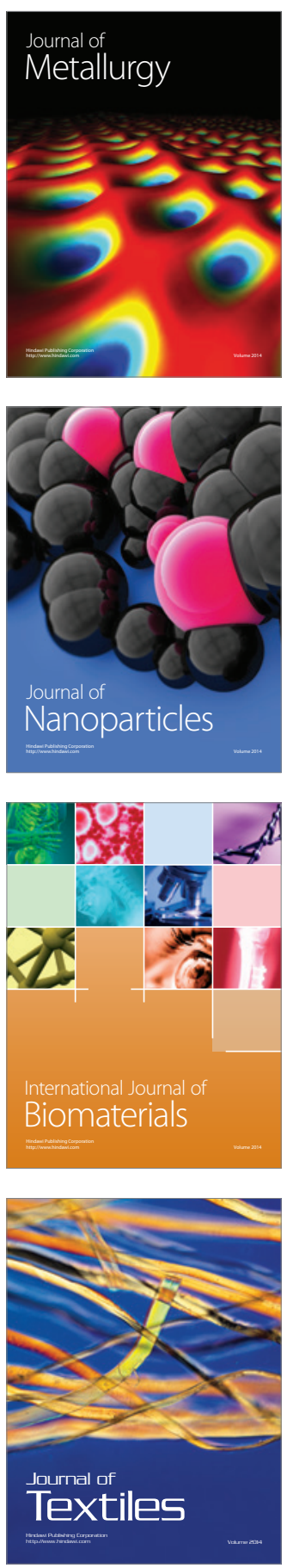